\title{
Temporary Nature-based Carbon Removal Can Lower Peak Warming in a Well-below $2^{\circ} \mathrm{C}$ Scenario
}

H. Damon Matthews ( $D$ damon.matthews@concordia.ca )

Concordia University https://orcid.org/0000-0003-3625-390X

Kirsten Zickfeld

Simon Fraser University https://orcid.org/0000-0001-8866-6541

Mitchell Dickau

Concordia University

Alexander Maclsaac

Simon Fraser University

\section{Sabine Mathesius}

GEOMAR, Helmholtz Centre for Ocean Research Kiel https://orcid.org/0000-0002-6912-1447

Claude-Michel Nzotungicimpaye

Concordia University

\section{Amy Luers}

Microsoft

\section{Article}

Keywords: Natural climate solutions (NCS), climate objectives, carbon removal, lower peak warming, $2^{\circ} \mathrm{C}$ scenario

Posted Date: November 12th, 2021

DOI: https://doi.org/10.21203/rs.3.rs-1025154/v1

License: (c) (1) This work is licensed under a Creative Commons Attribution 4.0 International License.

Read Full License

Version of Record: A version of this preprint was published at Communications Earth \&amp; Environment on March 17th, 2022. See the published version at https://doi.org/10.1038/s43247-022-00391-z. 
Temporary nature-based carbon removal can lower peak warming in a well-below $2^{\circ} \mathrm{C}$ scenario

H. Damon Matthews*1, Kirsten Zickfeld², Mitchell Dickau' ${ }^{1}$, Alex Maclsaac ${ }^{2}$, Sabine Mathesius ${ }^{2}$, Claude-

${ }^{1}$ Concordia University, Montreal, Canada

$9{ }^{2}$ Simon Fraser University, Vancouver, Canada

$10{ }^{3}$ Microsoft, Seattle, United States

11 *corresponding author: damon.matthews@concordia.ca

\section{Abstract}

There is growing recognition that meeting the climate objectives of the Paris Agreement will require the world to achieve net-zero carbon dioxide emissions around or before mid-century ${ }^{1-4}$. Natural climate solutions (NCS), which aim to preserve and enhance carbon storage in terrestrial or aquatic ecosystems $\mathrm{s}^{5,6}$, are increasingly being evoked as a potential contributor to net-zero emissions targets ${ }^{7,8}$. However, there is a risk that any carbon that we succeed in storing in land-based systems could be subsequently lost back to the atmosphere as a result of either climate-related or human-caused disturbances such as wildfire or deforestation ${ }^{9-12}$. Here we quantify the climate effect of NCS in a scenario where land-based carbon storage is enhanced over the next several decades, and this stored carbon is then returned to the atmosphere during the second half of this century. We show that temporary carbon sequestration has the potential to decrease the peak temperature increase, but only if implemented alongside an ambitious mitigation scenario where fossil fuel $\mathrm{CO}_{2}$ emissions were decreased to net-zero during the time that NCS-sequestered carbon remained stored. We also demonstrate the importance of non- $\mathrm{CO}_{2}$ climate effects of NCS implementation; decreases in surface albedo that result from temporary reforestation, for example, have the potential to counter almost half of the climate effect of carbon sequestration. Our results suggest that there is some climate benefit associated with NCS, even if the carbon storage is temporary, but only if implemented as a complement 
An increasing number of countries, cities and corporations are committing to net-zero greenhouse gas emissions targets in an effort to contribute to achieving the climate goals of the Paris Agreement ${ }^{1}$. Alongside these targets, there is increased attention on possible strategies to remove carbon dioxide from the atmosphere (so-called carbon dioxide removal or $C D R)^{13-15}$ which would be required to reach a global net-zero target if we do not succeed in eliminating all sources of emissions ${ }^{1}$. Among CDR approaches, natural climate solutions $(\mathrm{NCS})^{5-7}$ encompass a range of strategies aimed at preserving and enhancing carbon storage in ecosystems and on agricultural lands. A key appeal of NCS is the potential to contribute to climate mitigation efforts, while also generating additional co-benefits for human wellbeing and biodiversity ${ }^{16}$.

NCS include efforts to avoid additional land-use carbon emissions (e.g. by preventing additional deforestation), as well as enhance natural carbon removal processes (e.g. by reforestation of previously deforested areas) ${ }^{5-7}$. To contribute to climate mitigation efforts, NCS would need to slow the carbon loss from, and subsequently increase the amount of carbon stored in, natural systems. To contribute specifically to achieving net-zero emissions targets, NCS would need to achieve net carbon removal from the atmosphere beyond what would be achieved via natural processes only. To further contribute to limiting climate warming, we also need to ensure that NCS do not have additional climate effects that might counter the climate benefit of enhanced carbon sequestration ${ }^{17}$. And in all cases, the timescale over which carbon remains stored in nature is likely a key determinant of its net climate benefit.

Previous analyses of the global potential of NCS have suggested that a combination of avoided land-use $\mathrm{CO}_{2}$ emissions and enhanced carbon sequestration in natural systems could provide more than one third of the mitigation effort between now and 2030 that would be needed to stabilize warming below $2^{\circ} \mathrm{C}^{5}$.

59 This positioning of NCS-based mitigation activities as equivalent to and interchangeable with fossil fuel $60 \mathrm{CO}_{2}$ emissions reductions carries an implicit assumption that the removed (or not emitted) carbon will 61 be permanently sequestered. This is a critical assumption that has not been well acknowledged in the literature to date; indeed, anything less than permanent storage would result in only a temporary

63 climate benefit that would not match the multi-century to millennial-scale warming caused by fossil fuel

$64 \mathrm{CO}_{2}$ emissions ${ }^{4,18}$. However, the permanence of carbon storage in natural ecosystems cannot in reality 65 be guaranteed, given its vulnerability to both human-driven (e.g. deforestation or other land-use 
change) and climate-related (e.g. wildfire, drought or insect) disturbances that could occur at any time in

67 the foreseeable or unforeseeable future ${ }^{9,11,19,20}$. Quantifying the near-term carbon sequestration potential of NCS (as done by Refs ${ }^{5,8,21}$, for example) is therefore not sufficient to gauge the potential contribution of NCS to the long-term temperature goal of the Paris Agreement. Rather than assuming permanent storage via NCS, we should in fact assume that this carbon storage will be temporary and then ask: to what extent will temporary carbon sequestration via NCS contribute to meeting our climate mitigation goals?

Here we assess and quantify the climate and carbon cycle implications of nature-based carbon removal resulting in temporary storage in land ecosystems, when implemented alongside climate mitigation scenarios ranging in ambition from relatively weak (SSP2-4.5) to very strong (SSP1-1.9). We use an intermediate complexity global climate mode ${ }^{22}$ to simulate the near-term rate of temperature increase, the peak temperature change, and the long-term temperature trajectory in response to a set of emissions scenarios which include both global decarbonization efforts and temporary land-based enhanced carbon storage (see Methods). We simulated land-based sequestration first as an idealized scenario with prescribed $\mathrm{CO}_{2}$ removal, and second using the model's dynamic vegetation component to simulate an expansion of global forest cover. In both cases, the modelling setup reflects a case where NCS are used to withdraw carbon from the atmosphere over the next three decades, followed by the stored carbon being gradually released back to the atmosphere during the second half of this century.

\section{Idealized temporary carbon removal}

We implemented three idealized NCS scenarios based on estimates of the feasible potential of NCSbased carbon removal ${ }^{5,23}$, in which we prescribed an increasing rate of removal beginning in 2020, and reaching a maximum removal rate at 2030 of $3.64^{23}$ and $10.4^{5} \mathrm{Gt} \mathrm{CO}_{2}$ per year relative to the baseline scenario emissions (see Methods). In two of the scenarios, we then decreased this rate of removal after 2030 to zero at the year 2056, resulting in cumulative removals of 81 and $173 \mathrm{GtCO}_{2}$ in the two scenarios; in the third, we sustained the higher removal rate of $10.4 \mathrm{Gt} \mathrm{CO}_{2}$ per year until the year 2050 before decreasing it to zero at 2056, leading to a cumulative removal of $316 \mathrm{Gt} \mathrm{CO}_{2}$ (Figure $1 \mathrm{a}$ and $1 \mathrm{~d}$ ). In all three scenarios, this removed carbon was subsequently returned to the atmosphere after 2056 such that cumulative $\mathrm{CO}_{2}$ emissions at the year 2100 were equivalent to the baseline SSP scenarios. In response to this temporary carbon removal, mid-century atmospheric $\mathrm{CO}_{2}$ concentrations were 
decreased by between 7 and $28 \mathrm{ppm}$ across the two SSP and three carbon removal scenarios (Figure

99 1b). This represents a carbon removal effectiveness of between $63 \%$ and $69 \%$ (i.e. between $31 \%$ and

$10037 \%$ of the removed $\mathrm{CO}_{2}$ was offset by reduced carbon uptake by the land and ocean carbon cycle).

102 Given the absence of any physical land-surface changes in these simulations, the global temperature 103 response to this prescribed temporary carbon removal was closely proportional to the change in 104 cumulative $\mathrm{CO}_{2}$ emissions, reaching a maximum difference of between 0.04 and $0.17^{\circ} \mathrm{C}$ below the 105 temperatures in the SSP baseline scenarios (Figure 1c). This represents a global temperature response of 106 between 0.5 and $0.55^{\circ} \mathrm{C}$ per $1000 \mathrm{Gt} \mathrm{CO}_{2}$ removal, similar to that found in previous idealized carbon 107 removal experiments using this model ${ }^{24}$. In the case of the SSP1-1.9 scenario, this difference led to a 108 decreased peak temperature level of between 0.03 and $0.07^{\circ} \mathrm{C}$ (Figure 1e), whereas for SSP2-4.5 109 temperatures did not peak during the $21^{\text {st }}$ century and the effect of temporary carbon removal was 110 rather to delay the occurrence of a particular level of warming: by 0 to 1 year for $1.5^{\circ} \mathrm{C}$ and by 2 to 8 111 years for $2^{\circ} \mathrm{C}$ (Figure 1c). For both scenarios, the annual warming rate over the next three decades 112 decreased in response to the prescribed carbon removal, with subsequently higher rates during the 113 second half of the century. Both global temperature differences and changes to the rate of warming 114 were temporary effects in our simulations, returning to the level of the baseline SSP scenarios shortly 115 after the year 2100. 
a.

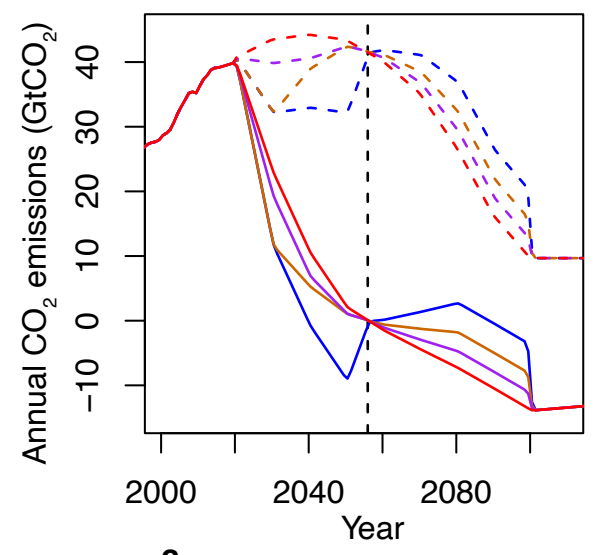

c. b.

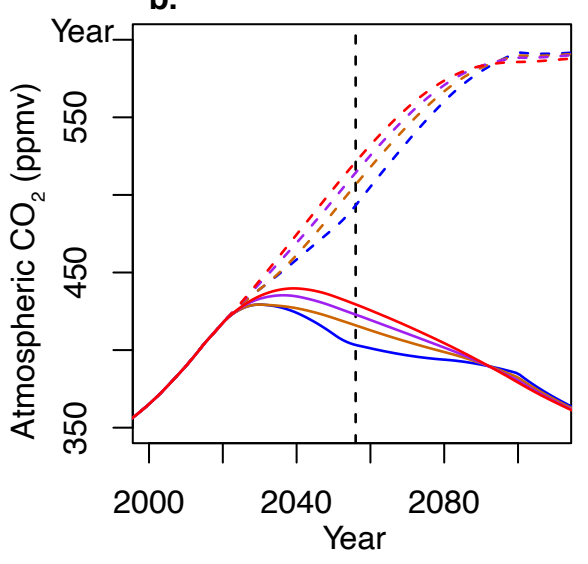

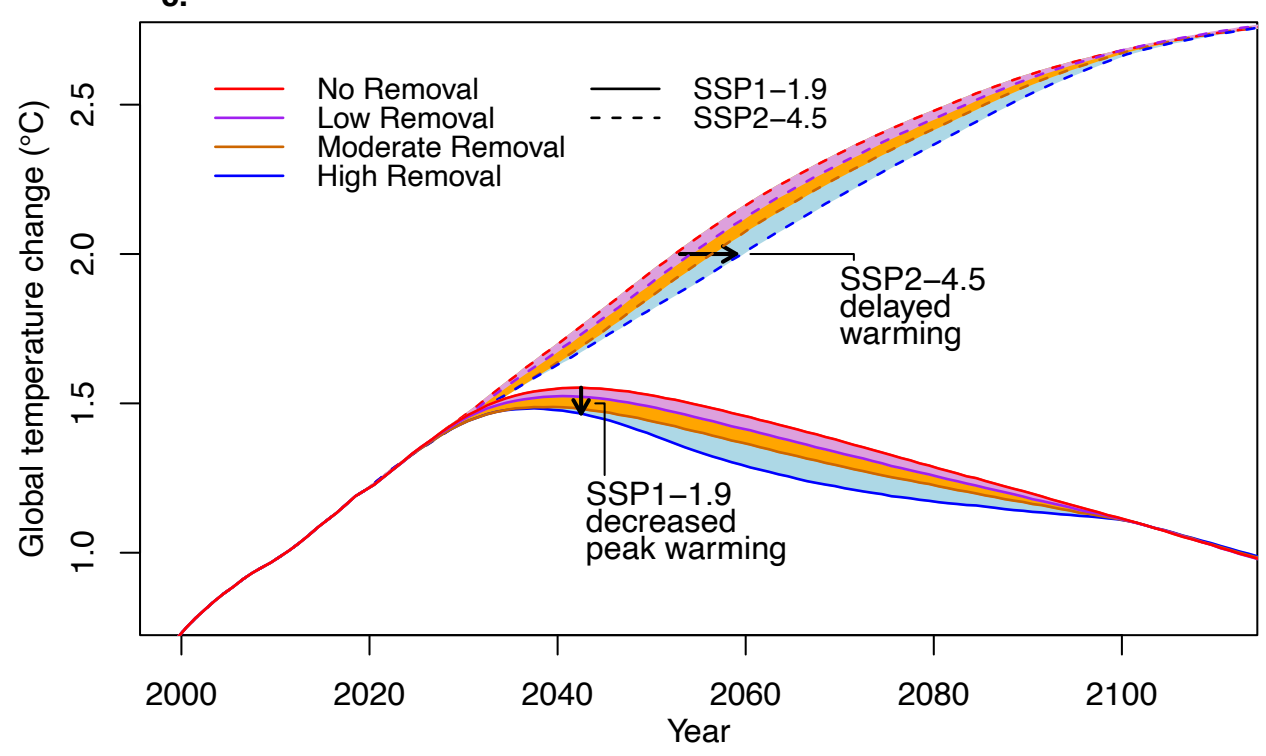

d. Cumulative removal

e. Maximum Temperature Increase
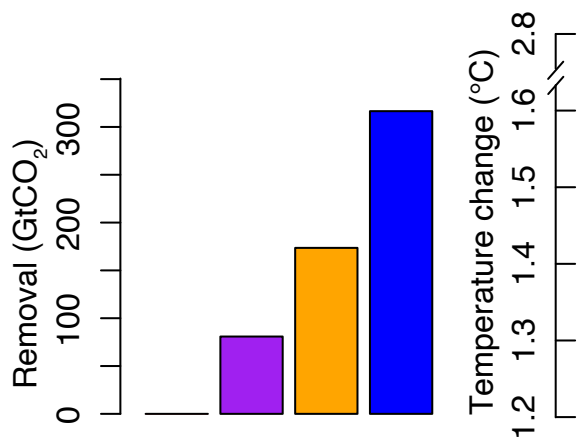

Figure 1: Climate response to prescribed temporary carbon removal scenarios. a and d: Prescribed $\mathrm{CO}_{2}$ removal and subsequent return to the atmosphere resulted in cumulative temporary removals of 81 (purple lines/bars), 173 (orange lines/bars) and 316 (blue lines/bars) $\mathrm{GtCO}_{2}$ relative to the baseline scenarios (red lines/bars). b: Atmospheric $\mathrm{CO}_{2}$ decreased by maximum amounts of 7 to $28 \mathrm{ppm}$ across scenarios in response to the prescribed removal. $\mathbf{c}$ and e: Global temperatures decreased by a maximum amount of 0.04 to 0.17 , relative to the baseline SSP scenarios, and in the SSP1-1.9 scenario peak temperatures decreased by between 0.03 and $0.07^{\circ} \mathrm{C}$. 
The simulations presented in Figure 1 show the potential climate response to a prescribed temporary carbon removal scenario, but do not represent any particular type of NCS, many of which would have additional climate effects beyond the removal of $\mathrm{CO}_{2}^{8,17}$. Most notable among potential secondary climate effects are potential surface albedo decreases that would result from changes in vegetation types associated with forest-based NCS such as afforestation and reforestation ${ }^{5,8}$. Here, we assessed the specific case of a temporary reforestation-based NCS scenario, in which we allowed forest distributions in the model to regrow to their historical (year 1920) extent between 2020 and 2056, and then gradually returned forest cover to their SSP scenario-projected distributions between 2056 and 2100 (see Methods). Modelled results therefore included both a temporary removal of atmospheric $\mathrm{CO}_{2}$ and the associated changes in surface albedo resulting from simulated forest cover changes.

Our SSP1-1.9 forest regrowth scenario led to an increase of approximately 4 million $\mathrm{km}^{2}$ of increased forested area in the model, resulting in an additional land carbon storage of $129 \mathrm{GtCO}_{2}$ at mid-century relative to the no-regrowth scenario (difference between blue and red lines in Figure 2a). This sequestered carbon was subsequently returned to the atmosphere by the year 2100 in response to the prescribed return to scenario-projected forest cover distributions at the end of the century. This increased land carbon storage resulted in a maximum atmospheric $\mathrm{CO}_{2}$ drawdown of $12.3 \mathrm{ppm}$ (Figure $2 \mathrm{~b}$ ) which represents $73 \%$ of the increased land carbon storage on account of decreased ocean carbon uptake in response to lower atmospheric $\mathrm{CO}_{2}$ levels. This carbon removal effectiveness is not directly comparable with that calculated in the idealized scenarios shown in Figure 1 however, because the increased land carbon storage that we have calculated here includes a secondary response of global land vegetation to the lower $\mathrm{CO}_{2}$ concentration induced by reforestation in our scenario; i.e. without this additional feedback, the land carbon increase in our simulations would have been higher than that indicated by the blue line in Fig. $2 a$.

The global temperature response to this reforestation-based carbon removal scenario was considerably less pronounced than in the idealized removal scenario on account of surface albedo decreases caused by expanded forest cover (Figure 2c). The maximum temperature difference caused by reforestation

157 reached $0.045^{\circ} \mathrm{C}$ at the time of maximum forest carbon increase, and peak temperatures in this 158 simulation were $0.022{ }^{\circ} \mathrm{C}$ lower than in the baseline simulation (Figure 2c). This represents a global 
159 temperature response to removal of $0.3^{\circ} \mathrm{C}$ per $1000 \mathrm{GtCO}_{2}$ of removal. Compared to the idealized case 160 in Figure $1\left(0.5\right.$ to $0.55^{\circ} \mathrm{C}$ per $1000 \mathrm{GtCO}_{2}$ of removal), this means that a unit removal of carbon via 161 global reforestation in our model is about $45 \%$ less effective at decreasing global temperatures as 162 compared to NCS strategies that do not affect land surface albedo. Indeed, when we removed the 163 albedo effect from the reforestation simulation (dashed green lines on Figure 2; see Methods) the 164 maximum temperature difference was $0.08^{\circ} \mathrm{C}$ (with a peak temperature decrease of $0.045^{\circ} \mathrm{C}$ ) 165 representing an equivalent global temperature effectiveness of removal as in the idealized removal 166 simulations. This results emphasizes the potentially significant non- $\mathrm{CO}_{2}$ effects of NCS implementation; 167 our model does not represent all such potential effects however, most notably the effect of changing 168 cloud cover in response to forest distribution changes ${ }^{25}$. It is likely therefore that including a more 169 complete representation of non-carbon effects would cause temperature changes in this scenario to fall 170 somewhere within the green shaded region of Figure $2 c$, rather than following either the blue or green 171 lines. 
a.

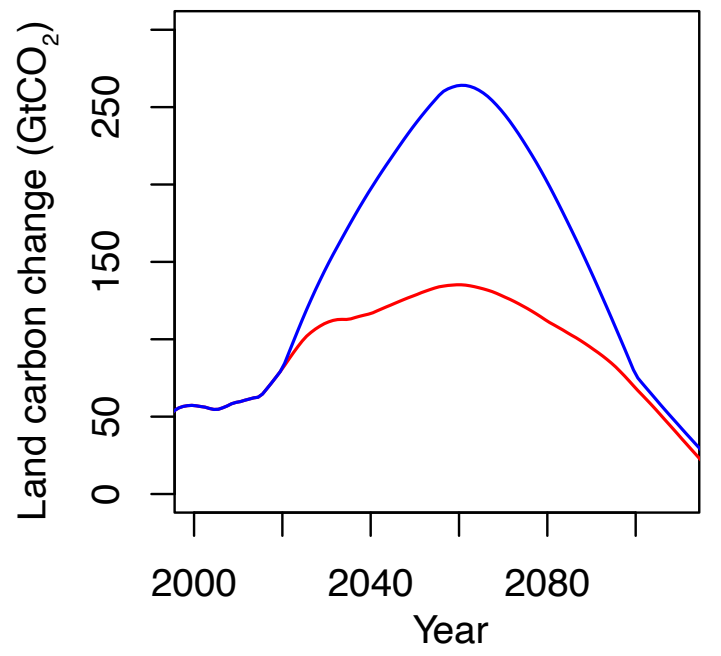

c. b.

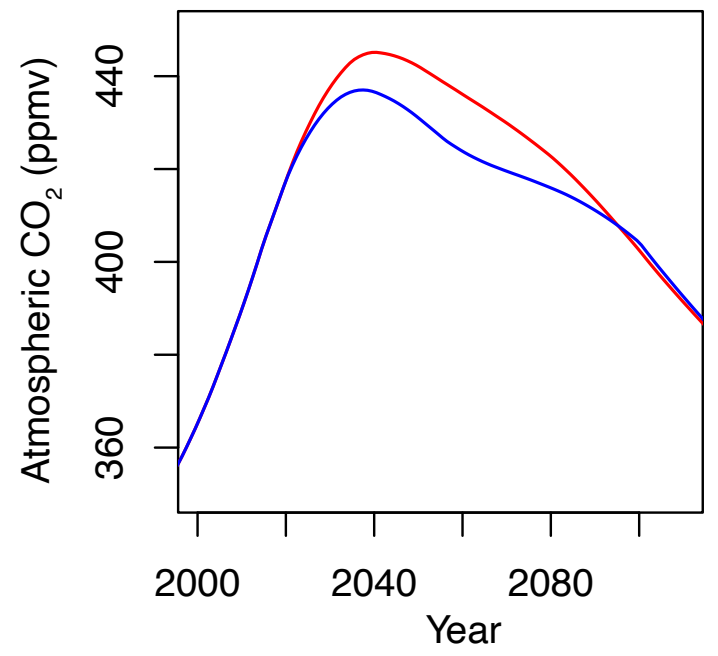

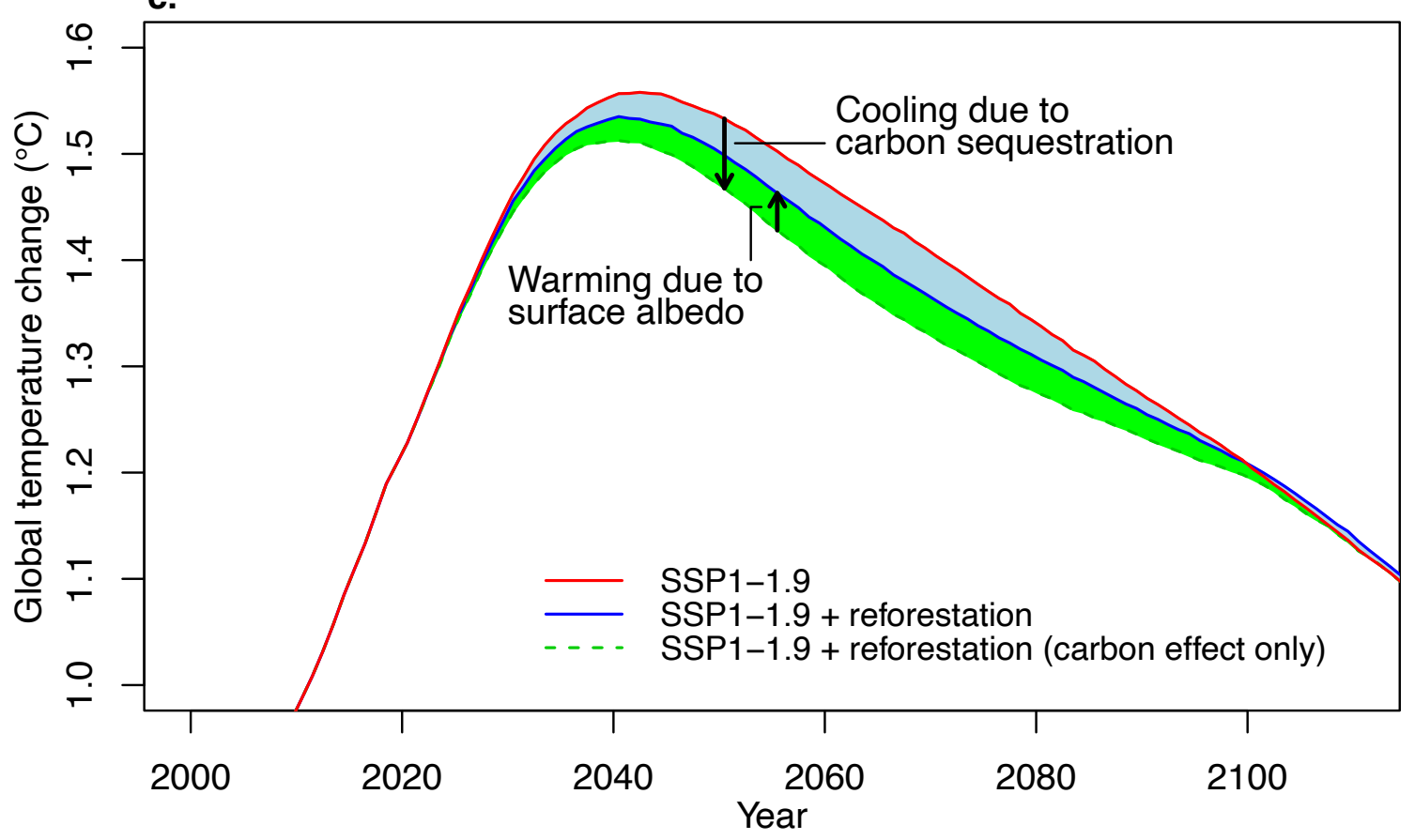

173 174

175

176

177

178

179

180

181

182

183

184

Figure 2: Climate response to a temporary reforestation-driven carbon removal scenario. a.

Reforestation to year 1920 forest extent led to an additional $129 \mathrm{GtCO} 2$ of land carbon storage relative to the baseline SSP1-1.9 scenario, which was subsequently returned to the atmosphere during the second half of this century. b. Atmospheric $\mathrm{CO}_{2}$ concentrations decreased by $12.3 \mathrm{ppm}$ in response to this increase land carbon storage. c. Peak temperature in this scenario decreased by $0.022^{\circ} \mathrm{C}$, with the maximum temperature decrease relative to baseline scenario reaching $0.045^{\circ} \mathrm{C}$ around the year 2060 . Land surface albedo decreases due to expanded global forest cover decreased this climate response by about $45 \%$ relative to the temperature change that would have occurred in the absence of albedo changes. 
185 The magnitude of the surface albedo offset to reforestation-based carbon removal varied considerably 186 depending on where reforestation occurred in our simulation. Our scenario of a reversed historical 187 deforestation pattern, resulted in a particular spatial pattern of land carbon increase (Figure 3a) that 188 reflects where our model's climate would support the growth of forests in regions that were converted 189 from natural vegetation cover to agriculture or pasture between 1920 and 2020. The resulting global 190 land surface albedo decrease was 0.0015 (0.15 percentage points), with regional decreases sometimes 191 exceeding 0.03 (3 percentage points) in areas of high reforestation. The climate consequence of this 192 pattern of surface albedo decreases (Figure 3b) shows a clear pattern of regional warming localized 193 around areas of forest carbon increase and associated surface albedo decrease. In contrast, the cooling 194 due to only carbon sequestration (Figure 3c) occurred globally, with larger cooling at higher latitudes 195 owing to positive feedbacks at high-latitude that amplified the response to lowered atmospheric $\mathrm{CO}_{2}$. 196 Consequently, though the global effect of reforestation in this model was to cool the climate, regions of 197 the highest level of reforestation showed a small regional warming on account of a regionally larger 198 albedo effect compared to the global effect of carbon sequestration at that location (Figure 3d). 


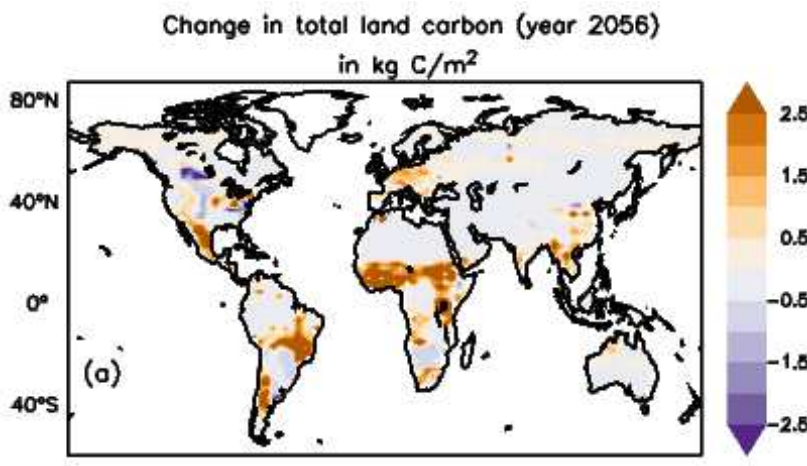

Change in SAT due to albedo only (2050-2060)

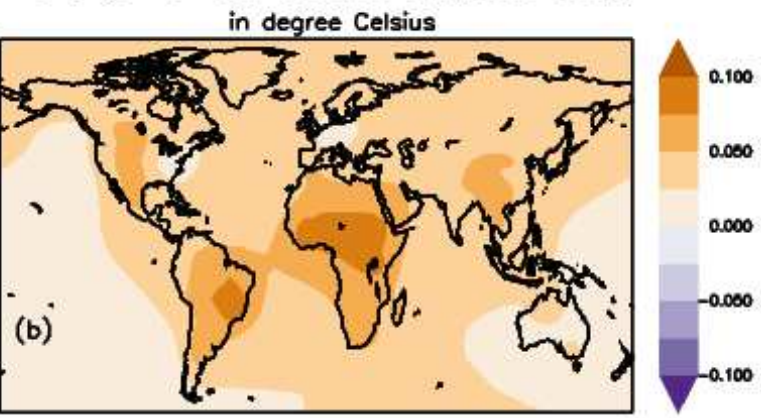

Change in SAT due to carbon uptake only (2050-2060)
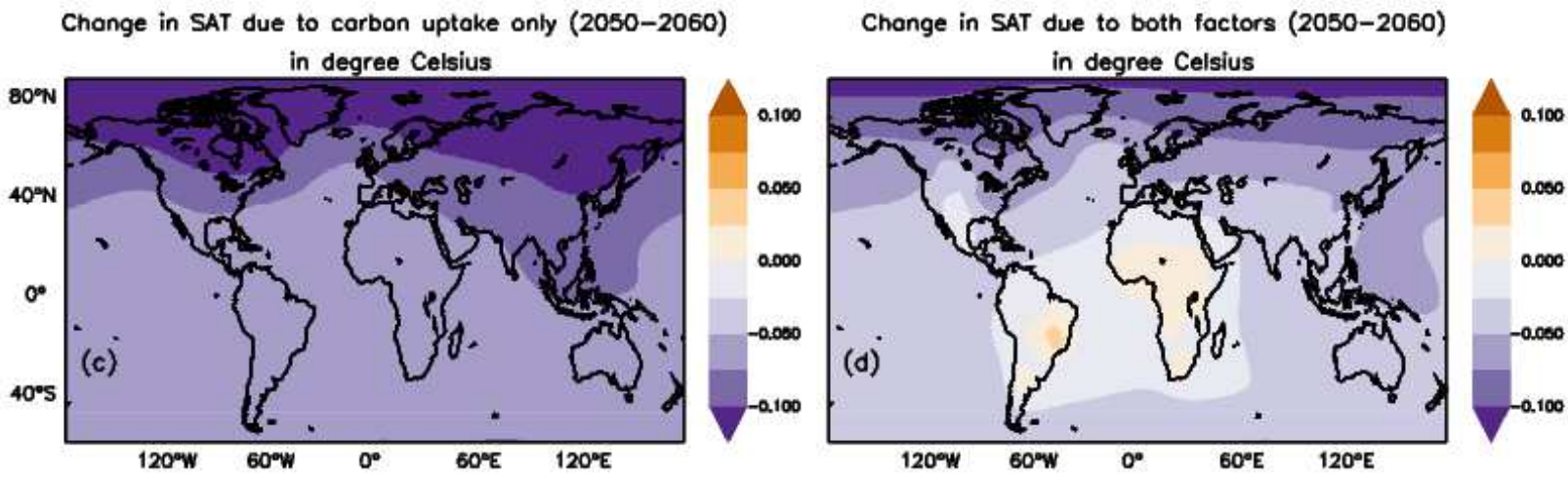

Figure 3: Spatial pattern of climate response to carbon sequestration and surface albedo changes resulting from temporary reforestation scenarios. a. Our scenario of reversed historical deforestation led to a global land carbon increase of $129 \mathrm{GtCO}_{2}$, which occurred primarily in tropical and subtropical regions. $\mathbf{b}$. The associate surface albedo decreases led to a spatial pattern of warming that was concentrated in areas of larger forest cover increase, whereas $\mathbf{c}$. the cooling due to carbon sequestration was larger at higher latitudes owing to regionally stronger climate feedbacks. $\mathbf{d}$. Consequently, the pattern of the net climate response to reforestation showed cooling over most of land areas, but a small net warming over some tropical continental regions. 


\section{The role of NCS in climate mitigation}

215 Our results show that successful carbon sequestration via NCS can have climate benefit, even in the case

216 that the carbon storage is temporary such that the stored carbon is returned to the atmosphere later

217 this century. However, the most important climate benefit - a decrease in the level of peak warming - is

218 only realized in a scenario where fossil fuel $\mathrm{CO}_{2}$ emissions are decreased rapidly to net-zero, resulting in

219 global temperatures that peak and decline during the time period that NCS-stored carbon remains

220 sequestered in nature. This implies that realizing a tangible climate benefit from NCS will require net-

221 zero fossil fuel $\mathrm{CO}_{2}$ emissions to be achieved on the same timescale as the successful implementation of

222 NCS. In the absence of this level of stringency in future mitigation effort, temporary NCS-based carbon

223 storage would not affect peak warming, and would serve only to delay the occurrence of a given

224 warming level, with no other long-term climate benefit.

226 Our results also demonstrate the need to better assess the potential non- $\mathrm{CO}_{2}$ climate effects of NCS.

227 Here, we quantified the effect of albedo changes associated with global reforestation efforts, and can

228 conclude that NCS methods that modify surface albedo will have a reduced climate benefit. Previous

229 discussions of NCS options have highlighted tropical forest reforestation as a more robust climate

230 strategy compared to high-latitude reforestation for exactly this reason ${ }^{5,21,26,27}$; our results suggest that

231 even tropical forest restoration has as a substantial albedo-related penalty associated with it, given that

232 our reforestation scenario resulted in primarily tropical and subtropical forest carbon sequestration. We

233 note, however, that our model is not able to simulate all of the non- $\mathrm{CO}_{2}$ effects of reforestation;

234 notably, we do not simulate changes in cloud cover, which have been shown to be a significant

235 determinant of the net climate response to both tropical and mid-latitude forest cover changes ${ }^{25}$.

236 Reviews of NCS options have also highlighted wetland restoration and soil carbon sequestration as "no-

237 regrets" options with few negative consequences ${ }^{16}$. We caution, however, that wetland restoration

238 would also change surface albedo, as well as the balance of carbon vs. methane emissions from the

239 landscape. Similarly, soil carbon sequestration could also lead to altered surface albedo, particularly if

240 achieved via the addition of biochar ${ }^{28,29}$. Following from our analysis, there is a need to quantify the full

241 Earth-system response to both reforestation and a broader range of other NCS approaches so as to be

242 able to better estimate the net climate response to these proposed solutions. 
244 Perhaps the most salient implication of our results is to challenge the prevailing narrative surrounding 245 the role of NCS in climate mitigation. Recent claims of the carbon storage potential of NCS ${ }^{5,6,8,21,30}$ have 246 generally positioned NCS as a contribution to climate mitigation that is interchangeable with other 247 emission reduction options. The framing of land-based mitigation as a potential emissions-reduction 248 "wedge" has been long-standing in the literature ${ }^{31,32}$, but fails to acknowledge that the climate effect of 249 nature-based carbon sequestration is only equivalent to a fossil fuel $\mathrm{CO}_{2}$ emissions reduction if: (1) the 250 carbon is permanently sequestered in nature; and (2) the additional non- $\mathrm{CO}_{2}$ effects of NCS are small 251 relative to the climate benefit of carbon sequestration. Our analysis here shows that if permanence is 252 not achieved, the climate benefit is also temporary, and that this benefit has the further potential to be 253 significantly weakened by non- $\mathrm{CO}_{2}$ climate effects. Both findings lead us to question the wedge-based 254 framework that positions NCS efforts as interchangeable with fossil fuel emissions reductions. Rather, 255 our finding that NCS could decrease peak warming requires that NCS be implemented independently 256 alongside a rapid transition to net-zero fossil fuel $\mathrm{CO}_{2}$ emissions, such that peak warming occurs before 257 climate- or human-induced disturbances cause NCS-sequestered carbon to be lost back to the 258 atmosphere.

There are of course many potential social and environmental benefits to investing in protecting and restoring nature, beyond carbon sequestration, which can also help mitigate climate risks ${ }^{5,33,34}$. Welldesigned stewardship or conservation of natural systems can have immediate and direct benefits to local environmental conditions, and could also benefit local and indigenous communities ${ }^{35}$. Biodiversity, water and air quality are valuable ecosystem services in and of themselves, and efforts to enhance these can also help to build community resilience to climate change $\mathrm{e}^{34-36}$. Our analysis suggests that near-term carbon sequestration potential could represent an additional co-benefit among a range of other environmental and social benefits resulting from improved nature stewardship and conservation. However, the climate mitigation potential of this carbon sequestration will likely only be realized if it is treated as an addition (and not an alternative) to stringent fossil fuel emission reductions. 
275 We used the University of Victoria Earth System Climate Model ${ }^{22,37}$ (UVic ESCM), an intermediate276 complexity global climate model which includes dynamic spatial vegetation changes and an interactive 277 land and ocean carbon cycle. This model is well suited to the efficient simulation of multi-century 278 climate responses to $\mathrm{CO}_{2}$ emissions and other climate forcings, and can additionally represent the 279 climate response to spatial land-use changes. This model has been used and validated extensively over 280 the past decade to look at research questions such as assessing the effect of historical land-use change 281 on climate, assessing the magnitude of climate-carbon cycle feedbacks, and quantifying the role of 282 terrestrial and oceanic carbon cycle process in the context of both past and future climate 283 scenarios ${ }^{18,38,39}$.

Using the UVic ESCM, we simulated the temporary storage of carbon via natural climate solutions (NCS) alongside two baseline climate mitigation scenarios: (1) SSP2-4.5, representing a weak climate mitigation scenario in which global $\mathrm{CO}_{2}$ emissions peak around 2030-2040 and then decrease (but remain positive) throughout the second half of the century; and (2) SSP1-1.9, representing an ambitious mitigation scenario with peak emissions at the year 2020 that decrease to net-zero at the year 2056 and then become net-negative throughout the remainder of the century. Other non- $\mathrm{CO}_{2}$ climate forcings were included in the simulations, based on observations for the historical period, and then following the forcing trajectories of SSP1-1.9 and SSP2-4.5, respectively. For both scenarios, temporary natural carbon removal was prescribed to occur between 2020 and 2056 (the net-zero year of SSP1-1.9). This stored carbon was then returned to the atmosphere between 2056 and 2100 such that at the year 2100 , the cumulative $\mathrm{CO}_{2}$ emissions across scenarios with and without natural carbon removal was equal.

We implemented this temporary carbon removal in two ways: first, as a perturbation to prescribed $\mathrm{CO}_{2}$ emissions in the model and second by allowing forests in the model to regrow to mid- $19^{\text {th }}$ century distributions. In the first case, this represents an idealized implementation of natural climate solutions, with no explicit modification of either the size of the modelled land carbon pool, or of the land surface characteristics that would be associated with the implementation of particular types of NCS. The second case reflects a reforestation-based NCS scenario, in which carbon is sequestered by the land carbon pool, and both vegetation distributions and the associated land-surface characteristics in the model change in associated with this additional carbon storage. 
For the first set of idealized carbon dioxide removal scenarios, we implemented carbon removal due to NCS by adjusting prescribed fossil fuel + land-use $\mathrm{CO}_{2}$ emissions to reflect the potential of nature-based carbon removal assessed by Refs ${ }^{23}$ and ${ }^{5}$. Prescribed $\mathrm{CO}_{2}$ emissions were decreased relative to the baseline scenario beginning in 2020, reaching a maximum difference of $3.64^{23}$ or $10.4^{5} \mathrm{GtCO}_{2}$ per year at the year 2030 below the baseline SSP scenario. After 2030, this maximum removal rate was gradually decreased to converge with the baseline emissions scenario at the year 2056, resulting in cumulative removals of $80.7 \mathrm{GtCO}_{2}$ and $173.3 \mathrm{GtCO}_{2}$ in the two scenarios, respectively. For the $10.4 \mathrm{GtCO}_{2}$ removal level, we also included a scenario in which this amount of annual removal was sustained until 2050 (following the projection of Ref ${ }^{5,33,34}$ ), and then decreased to zero annual removal at the year 2056, resulting in a cumulative removal of $316 \mathrm{GtCO}_{2}$. After the year 2056 , this removed $\mathrm{CO}_{2}$ was returned to the atmosphere by increasing prescribed emissions between 2056 and 2100 relative to the baseline scenario. In this set of simulations, spatial distributions of agricultural areas were prescribed up to the year 2020, after which land-use emissions were prescribed according to the carbon removal scenarios described above.

322

(2) Carbon removal via partial reforestation of agricultural areas

For the second set of simulations, we used prescribed changes in agricultural areas to allow the expansion of forest vegetation and subsequent terrestrial carbon removal to be simulated by the model's dynamic vegetation and carbon cycle components ${ }^{22}$. In the base simulation without carbon removal, we prescribed spatial changes in historical and future (scenario-determined) agricultural areas, with all other climate drivers (fossil fuel $\mathrm{CO}_{2}$ emissions and other climate forcings) equivalent to the idealized removal scenarios above. Beginning at the year 2020, we implemented a global reforestation scenario, in which global forested areas were allowed to regrow from 2020 until 2056 to return to their historical extent of the year 1920. This forest regrowth was then reversed between 2056 and 2100, returning forest cover to its scenario-projected distribution at the end of the century. 
337 surface albedo changes resulting from vegetation cover changes. To separate the effect of carbon

338 storage and surface albedo changes, we implemented a third simulation in which the $\mathrm{CO}_{2}$ concentration

339 from the reforestation scenario was used to drive a simulation that was otherwise equivalent to the

340 baseline (no reforestation) scenario; this third simulation therefore captured the climate effect of

341 enhanced land carbon storage in the absence of reforestation-induced surface albedo changes.

343 We note that in this set of simulations, we do not make any attempt to quantify or inform the discussion

344 of what are feasible or optimal locations for reforestation to occur so as to avoid conflict with other land

345 uses or with indigenous land rights ${ }^{35}$. We chose a forest regrowth pattern that reflects the reversal of

346 historical deforestation in this model so as to quantify the climate consequences of such reforestation

347 efforts, but not to argue that this pattern of reforestation has any particular rationale or merit. 


\section{References:}

1. Rogelj, J., Geden, O., Cowie, A. \& Reisinger, A. Three ways to improve net-zero emissions targets. Nature 591, 365-368.

2. Damon Matthews, H. et al. An integrated approach to quantifying uncertainties in the remaining carbon budget. Commun. Earth Environ. 2, 7 (2021).

3. Davis, S. J. et al. Net-zero emissions energy systems. Science 360, eaas9793 (2018).

4. Matthews, H. D. \& Caldeira, K. Stabilizing climate requires near-zero emissions. Geophys. Res. Lett. 35, L04705 (2008).

5. Griscom, B. W. et al. Natural climate solutions. Proc. Natl. Acad. Sci. 114, 11645-11650 (2017).

6. Bossio, D. A. et al. The role of soil carbon in natural climate solutions. Nat. Sustain. 3, 391-398 (2020).

7. Girardin, C. A. J. et al. Nature-based solutions can help cool the planet - if we act now. Nature 593, 191-194 (2021).

8. Drever, C. R. et al. Natural climate solutions for Canada. Sci. Adv. 7, eabd6034 (2021).

9. Anderegg, W. R. L. et al. Climate-driven risks to the climate mitigation potential of forests. Science 368, eaaz7005 (2020).

10. Landry, J.-S., Matthews, H. D. \& Ramankutty, N. A global assessment of the carbon cycle and temperature responses to major changes in future fire regime. Clim. Change 14 (2015).

11. Harper, A. B. et al. Land-use emissions play a critical role in land-based mitigation for Paris climate targets. Nat. Commun. 9, 2938 (2018).

12. Erb, K.-H. et al. Unexpectedly large impact of forest management and grazing on global vegetation biomass. Nature 553, 73-76 (2018).

13. Rickels, W., Reith, F., Keller, D., Oschlies, A. \& Quaas, M. F. Integrated Assessment of Carbon Dioxide Removal. Earths Future 6, 565-582 (2018).

14. Cao, L. \& Caldeira, K. Atmospheric carbon dioxide removal: long-term consequences and commitment. Environ. Res. Lett. 5, 024011 (2010).

15. Keller, D. P. et al. The Effects of Carbon Dioxide Removal on the Carbon Cycle. Curr. Clim. Change Rep. 4, 250-265 (2018).

16. Smith, P. et al. Land-Management Options for Greenhouse Gas Removal and Their Impacts on Ecosystem Services and the Sustainable Development Goals. Annu. Rev. Environ. Resour. 44, 255286 (2019).

17. Canadell, J. G. et al. Global Carbon and other Biogeochemical Cycles and Feedbacks. in Climate Change 2021: The Physical Science Basis. Contribution of Working Group I to the Sixth Assessment Report of the Intergovernmental Panel on Climate Change 177 (Cambridge University Press, in press).

18. Eby, M. et al. Lifetime of Anthropogenic Climate Change: Millennial Time Scales of Potential $\mathrm{CO}_{2}$ and Surface Temperature Perturbations. J. Clim. 22, 2501-2511 (2009).

19. Pugh, T. A. M., Arneth, A., Kautz, M., Poulter, B. \& Smith, B. Important role of forest disturbances in the global biomass turnover and carbon sinks. Nat. Geosci. 12, 730-735 (2019).

20. Wang, J. A., Baccini, A., Farina, M., Randerson, J. T. \& Friedl, M. A. Disturbance suppresses the aboveground carbon sink in North American boreal forests. Nat. Clim. Change 11, 435-441 (2021). 
21. Griscom, B. W. et al. National mitigation potential from natural climate solutions in the tropics. Philos. Trans. R. Soc. B Biol. Sci. 375, 20190126 (2020).

22. Mengis, N. et al. Evaluation of the University of Victoria Earth System Climate Model version 2.10 (UVic ESCM 2.10). Geosci. Model Dev. 13, 4183-4204 (2020).

23. Roe, S. et al. Contribution of the land sector to a $1.5^{\circ} \mathrm{C}$ world. Nat. Clim. Change 9, 817-828 (2019).

24. Zickfeld, K., Azevedo, D., Mathesius, S. \& Matthews, H. D. Asymmetry in the climate-carbon cycle response to positive and negative $\mathrm{CO}_{2}$ emissions. Nat. Clim. Change 11, 613-617 (2021).

25. Cerasoli, S., Yin, J. \& Porporato, A. Cloud cooling effects of afforestation and reforestation at midlatitudes. Proc. Natl. Acad. Sci. 118, e2026241118 (2021).

26. Koch, A., Brierley, C. \& Lewis, S. L. Effects of Earth system feedbacks on the potential mitigation of large-scale tropical forest restoration. Biogeosciences 18, 2627-2647 (2021).

27. Arora, V. K. \& Montenegro, A. Small temperature benefits provided by realistic afforestation efforts. Nat. Geosci. 4, 514-518 (2011).

28. Paustian, K. et al. Climate-smart soils. Nature 532, 49-57 (2016).

29. Smith, P. et al. Biophysical and economic limits to negative $\mathrm{CO}_{2}$ emissions. Nat. Clim. Change 6, 4250 (2016).

30. Fargione, J. E. et al. Natural climate solutions for the United States. Sci. Adv. 4, eaat1869 (2018).

31. Pacala, S. \& Socolow, R. Stabilization Wedges: Solving the Climate Problem for the Next 50 Years with Current Technologies. Science 305, 968-972 (2004).

32. Johnson, N., Gross, R. \& Staffell, I. Stabilisation wedges: measuring progress towards transforming the global energy and land use systems. Environ. Res. Lett. 16, 064011 (2021).

33. Seddon, N. et al. Understanding the value and limits of nature-based solutions to climate change and other global challenges. Philos. Trans. R. Soc. B Biol. Sci. 375, 20190120 (2020).

34. Fargione, J. E. et al. Natural climate solutions for the United States. Sci. Adv. 4, eaat1869 (2018).

35. Seddon, N. et al. Getting the message right on nature-based solutions to climate change. Glob. Change Biol. 27, 1518-1546 (2021).

36. Seddon, N., Turner, B., Berry, P., Chausson, A. \& Girardin, C. A. J. Grounding nature-based climate solutions in sound biodiversity science. Nat. Clim. Change 9, 84-87 (2019).

37. Weaver, A. J. et al. The UVic earth system climate model: Model description, climatology, and applications to past, present and future climates. Atmosphere-Ocean 39, 361-428 (2001).

38. Matthews, H. D., Weaver, A. J., Meissner, K. J., Gillett, N. P. \& Eby, M. Natural and anthropogenic climate change: incorporating historical land cover change, vegetation dynamics and the global carbon cycle. Clim. Dyn. 22, 461-479 (2004).

39. Zickfeld, K., Eby, M., Matthews, H. D., Schmittner, A. \& Weaver, A. J. Nonlinearity of Carbon Cycle Feedbacks. J. Clim. 24, 4255-4275 (2011). 